
\title{
28 Research Suare \\ COVID-19 and Mental Health: a Longitudinal Population Study from Norway
}

Hans Hvide ( $\nabla$ hans.hvide@uib.no)

Universitetet i Bergen https://orcid.org/0000-0002-2604-3696

Julian Johnsen

SNF: Samfunns- og naringslivsforskning AS

\section{Short Report}

Keywords: primary care, mental health, psychological disorder, psychological symptoms, covid-19, social distancing

Posted Date: June 29th, 2021

DOl: https://doi.org/10.21203/rs.3.rs-503626/v1

License: (1) This work is licensed under a Creative Commons Attribution 4.0 International License. Read Full License

Version of Record: A version of this preprint was published at European Journal of Epidemiology on January 27th, 2022. See the published version at https://doi.org/10.1007/s10654-021-00836-3. 


\section{Abstract}

Existing research has found negative short-term consequences of the COVID-19 pandemic on mental health problems, but longer-term effects have been less documented. Using newly released register data on all general practitioner consultations in Norway through 2020 (about 14 million consultations in total), we find that during the spring and early summer 2020, the number of psychological cases initially increased relative to prior years, but then fell back towards the level of prior years during the summer 2020. In early September 2020, the number of cases accelerated, a pattern that held up through December 2020, so that the gap between 2020 and prior years became largest end-of-year. Our findings suggest that the accumulated effects of the COVID-19 pandemic on mental health far exceeds the shortterm effects. The effects were particularly strong for females and for residents in urban areas.

\section{Introduction}

Many researchers have investigated the short-term consequences of the COVID-19 pandemic on mental health problems. Evidence from several countries suggest that the fear of infection and death from COVID-19, income insecurities, and limit to personal freedoms led to an increase in depression, anxiety, and substance abuse in the spring and early summer of 2020. (1, 2, 3, 4). Evidence on the longer-term effects is scarce (5). People may have developed better coping strategies, but the accumulated effects of stress may take its toll. We use near real-time register data covering the universe of general practitioner consultations in Norway through 2020 to address this issue.

\section{Materials And Methods}

The KUHR register data form the basis of the analysis.[1] KUHR cover all patient encounters with general practitioners in Norway, and we use the years 2017-2020. Each row in the data consist of a single encounter and includes one or more codes classifying the patient's condition. In addition, the data contain the date, time, and type of encounter.

From KUHR we selected the GP consultations.[2] The total number of GP consultations in 2020 was about 14 million, and about 1.8 million (14\%) resulted in at least one P-diagnosis. The percentage of the population that consulted a GP in 2020 was $75 \%$, identical to the prior years, due to a fast transition to electronic consultations after the COVID-19 outbreak in March 2020 (see the Supplementary Appendix).[3]

The diagnostical codes assigned in KUHR are according to the ICPC-2 classification system (International Classification of Primary Care) developed by WONCA (World Organization of Family Doctors) in 1987. ICPC-2 is a classification method for primary care encounters that includes codes both for the patient's reason for encounter and for diagnoses. The psychological codes P01-P99 are divided into symptoms and complaints (P01-P29) and diagnoses (P70-P99). For example, P03 "Feeling depressed" is a symptom/complaint and P76 "Depressive disorder" is a diagnosis.[4] 
We merged the KUHR with sociodemographic registers (also covering the whole population) using the unique person ID. The ID is an anonymized version of an individual's social security number. This allowed us to merge in gender, age, and municipality of residence variables for each patient.

As outcome variable, we focused on the number of weekly GP consultations from January 1 to December 31,2020 that resulted in a psychological diagnosis under ICPC-2, which we for convenience refer to as Pcases. We used the years 2017-2019 as a comparison group. We analyzed both percentage increases and increases per capita, population-wide and for subpopulations. We also analyzed the increase in cases for the eight most common psychological diagnoses in 2019 , i.e., pre-pandemic.

Poisson regressions were used to assess statistical significance. We regressed average number of weekly cases in week 40-51 on a dummy for year 2020. The coefficients of the regressions can be interpreted as percentage increases from 2017-2019 to 2020.

All analysis has been performed using Stata version 16.1. To define weeks, we use Stata's inbuilt time functions, the egen command with its week extension. As week 52 in Stata has different length in different years, it has been excluded from the analysis (the gap between 2020 and 2017-2019 is larger in week 52 than in prior weeks).

\section{Results}

Figure 1 depicts the population-wide weekly P-cases for 2020 (red line) using the 2017-2019 average (black line) for comparison. After the Covid-19 outbreak in March 2020 (vertical dashed line), the number of P-cases in 2020 became larger than the 2017-2019 in late spring, but more similar during summer. In early September, the gap between 2020 and 2017-2019 started increasing, a pattern that held up through December 2020.

Table 1 reports the number of cases in September-December 2020 (weeks 40-51), compared to the same period in 2017-2019. Panel A shows that the increase in P-cases in 2020 was about $17 \%$ [ $95 \% \mathrm{Cl}, 0.16$ 0.19] relative to 2017-2019. For non-severe diagnoses the increase in P-cases in 2020 was about $22 \%$ $(95 \% \mathrm{Cl}, 0.20-0.24)$, while for severe diagnoses the corresponding increase was about $13 \%(95 \% \mathrm{Cl}, 0.11-$ $0.15)$.

Panel B of Table 1 shows that the largest percentage increase was for age 11-17 (0.22; $95 \% \mathrm{Cl}, 0.16-0.29)$, age $65+(0.24 ; 95 \% \mathrm{Cl}, 0.20-0.28)$, for females $(0.19 ; 95 \% \mathrm{Cl}, 0.18-0.21)$ and for urban $(0.22 ; 95 \% \mathrm{Cl}, 0.18$ 0.25 ), the latter being inhabitants of the four largest Norwegian cities (Oslo, Bergen, Trondheim, Stavanger).

Panel C of Table 1 shows the percentage increase in cases in September-December 2020 relative to the same period in 2017-2019 for the eight most common (in 2019) psychological diagnoses. All eight increase substantially, especially hyperkinetic disorder (ADHD) and PTSD, about $36 \%$ [95\% $\mathrm{Cl}, 0.30-0.43]$ and about $33 \%[95 \% \mathrm{Cl}, 0.26-0.40]$. 
Figure 2 shows weekly increase of P-cases in 2020 compared to the 2017-2019 average (the shaded area in the top panel of Figure), at a per capita level. The bold line depicts a population-wide weekly increase of about 1 per 1000 capita in June-August, which doubled to about 2 end-of-year. Females, age 31-64, and urban areas experienced the larger per capita increases.

\section{Discussion}

The number of psychological cases in Norway was high relative to prior years in late spring and early summer 2020, consistent with evidence from other countries $(1,2,3,4)$, but then fell back towards pre-2020 levels during July and August, as depicted in Figure 1. Our main finding is the acceleration of cases starting September 2020 and still present end-of-year, also depicted in Figure 1 and Table 1. At a percapita level, the increase in weekly cases relative to prior years was about 1 per 1000 capita in JulyAugust and doubled to 2 per 1000 capita in December, as depicted in Figure 2. The acceleration of psychological cases during fall 2020 suggests that the accumulated effects of stress in the fall of 2020 outweighed the development of better coping strategies in the population.

As Norway had low incidence of Covid-19 cases and deaths during fall 2020 compared to many other countries, it seems plausible that the acceleration in cases during fall was due to accumulated effects of lockdowns and movement restrictions (rather than stress due to fear of infection).[5] As lockdowns and movement restrictions have been implemented worldwide, our findings should be of global interest to policy makers who contemplate the difficult trade-offs of continued lockdown policies. Our findings also have broader interest, in providing detailed population-level documentation of the mental health effects of prolonged shutdowns and limits to social interaction.

The main cities have been hubs for Covid-19 cases and lockdowns, as many metropolitan areas globally, and experienced larger increases during September-December than more rural areas, both at a per-capita and percentage level. The increases were also large for females. The adolescents (11-17 age) experienced a large percentage increase relative to other groups (but a lower per-capita increase).

As can be seen in Figure 1, the number of psychological cases in Norway were unusually high in January 2020. We are not aware of institutional changes that could explain this spike. One explanation could be that the unusually foul weather in January 2020 led to a "lockdown" created by nature.[6] In Table 1 we control for a possible "2020 effect" unrelated to COVID-19 by comparing the increase in average weekly cases during weeks 40-51 in 2020 to the corresponding increase during weeks 1-10 of 2020 (i.e., prior to the outbreak). The estimate from this approach (Panel A of Table 1) implies that the extra increase in Pcases during weeks $40-51$ in 2020 was $9 \%$, i.e., substantial.

As can be seen from Figure 1 (black line), Norway is characterized by a "long winter" effect, in that the number of P-cases are typically increasing during the fall months (9), possibly due to lack of sun exposure (10). To investigate whether the "long winter" effect possibly interacts with the COVID-19 effects, in Panel B of Table 1 we analyzed the increases in P-cases for the three northern-most counties (Nordland, Troms, and Finnmark) where the population live close to or above the arctic circle. The 
percentage increase, about $9 \%(95 \% \mathrm{Cl}, 0.04-0.15)$, is lower than the increase for the overall population (the first row), which suggest that the long winter effects are not driving our results.

\section{Declarations}

\section{Funding}

None

\section{Conflicts of interest/Competing interests}

None

\section{Ethics approval}

Obtained from NSD and Datatilsynet Norway

Consent to participate

Not applicable

Consent for publication

Obtained from NSD and Datatilsynet Norway

\section{Availability of data and material}

Data is proprietary but data access can be obtained, upon paying a cost for data production, for any researcher located in Norway

Code availability

Yes

\section{Authors' contributions}

Equal

\section{References}

1. McGinty EE, et al. Psychological distress and loneliness reported by US adults in 2018 and april 2020. JAMA. 2020;324(1):93-4. doi:10.1001/jama.2020.9740.

2. Pierce M, et al., (2020). Mental health before and during the COVID-19 pandemic: a longitudinal probability sample survey of the UK population. Lancet Psychiatry; 7: 883-92. https://doi.org/10.1016/ S2215-0366(20)30308-4. 
3. Pan KY, et al. The mental health impact of the COVID-19 pandemic on people with and without depressive, anxiety, or obsessive-compulsive disorders: a longitudinal study of three Dutch casecontrol cohorts. Lancet Psychiatry. 2021;8(2):121-9. https://doi.org/10.1016/S22150366(20)30491-0.

4. Wang Y, et al., (2021). The impact of quarantine on mental health status among general population in China during the COVID-19 pandemic. Molecular Psychiatry. Published online January 2021. doi: 10.1038/s41380-021-01019-y.

5. Salanti G, et al., (2021). An efficient way to assess the effect of COVID-19 on mental health in the general population. Lancet Psychiatry, Published Online March 16, 2021. S2215-0366(21)00067 - 5.

6. Gunnes $\mathrm{N}$, et al. Seasonal and pandemic influenza during pregnancy and risk of fetal death: A Norwegian registry-based cohort study. Eur J Epidemiol. 2020;35:371-9.

7. Mansfield KE, et al. Indirect acute effects of the COVID-19 pandemic on physical and mental health in the UK: a population-based study. The Lancet Digital Health. 2021;3(4):e217-30.

8. Holland KM, et al., (2021). Trends in US emergency department visits for mental health, overdose, and violence outcomes before and during the COVID-19 pandemic. JAMA psychiatry. Published online February 03, 2021. https://doi.org /10.1001/jamapsychiatry.2020.4402.

9. Øverland S, et al., (2020). Seasonality and symptoms of depression: A systematic review of the literature. Epidemiology psychiatric sciences, 29. doi:10.1017/S2045796019000209.

10. Lambert GW, et al. Effect of sunlight and season on serotonin turnover in the brain. The Lancet. 2002;360(9348):1840-2. doi:10.1016/s0140-6736(02)11737-5.

\section{Tables}

Table 1. P-cases in week 40-51, 2020, vs. average P-cases week 40-51 in 2017-19 
Avg. number of weekly cases $\quad \begin{gathered}\text { Output from Poisson } \\ \text { regression }\end{gathered}$

2017- $2020 \quad$ Difference $\quad$ Coeff. $\quad 95 \%$ CI $\quad$ p-value

19

Panel A. All (age 11+)

P-cases

$\begin{array}{llllll}35,610 & 42,387 & 6,777 & 0.17 & 0.16-0.19 & <0.001\end{array}$

Non-severe P-cases

$16,276 \quad 20,359$

4,083

0.22

$0.20-0.24<0.001$

Severe P-cases

$20,060 \quad 22,912$

2,852

0.13

$0.11-0.15<0.001$

P-cases, controlling for

$0.09 \quad 0.07-0.11<0.001$

week 1-10

Panel B. Subgroup P-cases

\begin{tabular}{lrrrrrr}
\hline Age 11-17 & 1,444 & 1,807 & 363 & 0.22 & $0.16-0.29$ & $<0.001$ \\
\hline Age 18-30 & 7,253 & 8,356 & 1,103 & 0.14 & $0.11-0.17$ & $<0.001$ \\
\hline Age 31-64 & 21,909 & 25,872 & 3,963 & 0.17 & $0.15-0.18$ & $<0.001$ \\
\hline Age 65+ & 5,004 & 6,352 & 1,348 & 0.24 & $0.20-0.28$ & $<0.001$ \\
\hline Male & 13,631 & 15,682 & 2,051 & 0.14 & $0.12-0.16$ & $<0.001$ \\
\hline Female & 21,979 & 26,705 & 4,726 & 0.19 & $0.18-0.21$ & $<0.001$ \\
\hline Urban & 5,002 & 6,219 & 1,217 & 0.22 & $0.18-0.25$ & $<0.001$ \\
\hline Rural & 25,605 & 29,949 & 4,344 & 0.16 & $0.14-0.17$ & $<0.001$ \\
\hline Northern-most counties & 2,498 & 2,737 & 239 & 0.09 & $0.04-0.15$ & 0.001
\end{tabular}

C. 8 most common psychological diagnoses/symptoms

$\begin{array}{lllllll}\text { P01 Feeling anxious } & 2,657 & 3,194 & 537 & 0-18 & 0.13-0.24 & <0.001\end{array}$

$\begin{array}{lllllll}\text { P02 Acute stress reaction } & 3,945 & 4,724 & 779 & 0.18 & 0.14-0.22 & <0.001\end{array}$

$\begin{array}{lllllll}\text { P03 Feeling depressed } & 1,570 & 2,023 & 453 & 0.25 & 0.19-0.32 & <0.001\end{array}$

$\begin{array}{lllllll}\text { P06 Sleep disturbance } & 3,380 & 4,406 & 1,026 & 0.27 & 0.22-0.31 & <0.001\end{array}$

$\begin{array}{lllllll}\text { P29 Psych. symptom other } & 3,608 & 4,321 & 713 & 0.18 & 0.14-0.22 & <0.001\end{array}$

$\begin{array}{lllllll}\text { P73 Affective psychosis } & 1,225 & 1,453 & 228 & 0.17 & 0.09-0.25 & <0.001\end{array}$

$\begin{array}{lllllll}\text { P74 Anxiety disorder } & 2,963 & 3,677 & 714 & 0.22 & 0.17-0.26 & <0.001\end{array}$

$\begin{array}{lllllll}\text { P76 Depressive disorder } \quad 8,980 & 10,235 & 1,255 & 0.13 & 0.10-0.16 & <0.001\end{array}$

$\begin{array}{lllllll}\text { P81 Hyperkinetic disorder } & 1,420 & 2,044 & 624 & 0.36 & 0.30-0.43 & <0.001\end{array}$

$\begin{array}{lllllll}\text { P82 PTSD } & 1,263 & 1,761 & 498 & 0.33 & 0.26-0.40 & <0.001\end{array}$

Notes: A "P-case" is a GP consultation that resulted in a psychological diagnosis based on the ICPC-2 classification system. In row 4, we used four observations: average weekly cases for week 1-10 in 2017-19, average weekly cases for week 40-51 in 201719 , average weekly cases for week 1-10 in 2020, and average weekly cases for week 40-51 in 2020. Using this sample, we ran a Poisson regression, regressing average number of weekly cases on a dummy for year 2020, a dummy for week 40-51, and the interaction of year 2020 and week 40-51. We report the coefficient of this interaction, which can be interpreted as the extra percentage increase in average weekly cases from 2017-19 to 2020 compared to the increase in average weekly cases from 2017-19 to 2020 for the pre-Covid part of the calendar year. 


\section{Footnotes}

[1] The KUHR data have been used extensively for academic research, see e.g., (6).

[2] These are encounter codes $2 a$ and $2 e$. The other GP encounters include tests without patient visits, extra time needed for a consultation (this extra time will be added as a separate row in the data), writing of prescriptions and doctor's certificates without consultation etc. These encounter types are usually not included in the official statistics by Statistics Norway.

[3] (6) and (7) document a large drop in GP encounters in the months after the COVID-19 outbreak in the UK and the US.

[4] https://ehelse.no/kodeverk/icpc-2e-english-version contains more information on ICPC-2, including a mapping to ICD-10.

[5] Our World in Data (2021). Norway: Coronavirus Pandemic Country Profile. Retrieved on 22.04.2021 from https://ourworldindata.org/coronavirus/country/norway

[6] January 2020 was the wettest January ever in Norway. See e.g., https://kommunikasjon.ntb.no/pressemelding/januar-2020-ble-den-vateste-noen-gang? publisherld $=17846853 \&$ releaseld $=17878908$

\section{Figures}




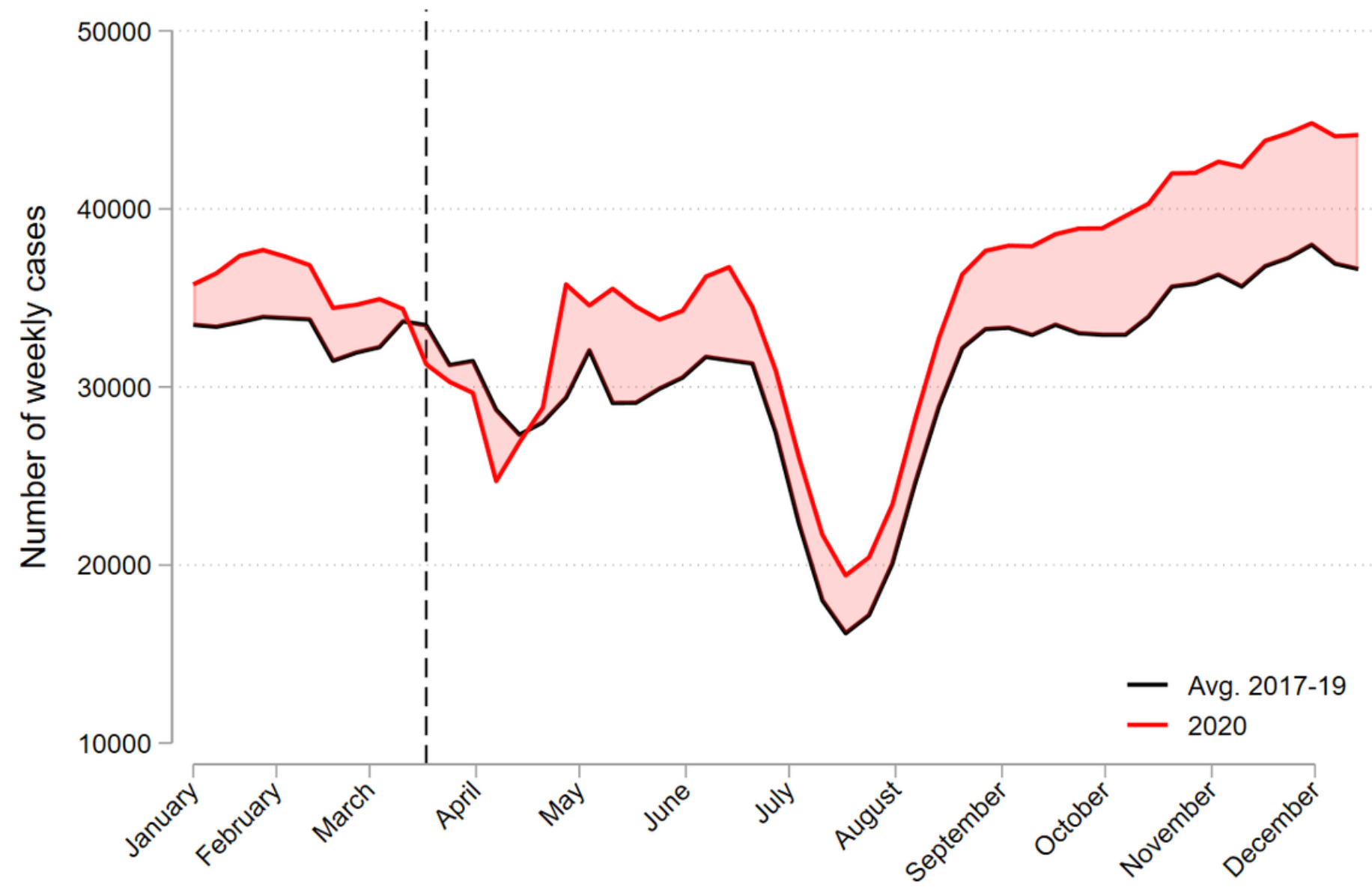

Figure 1

Weekly number of P-cases in 2020 (red line) vs. 2017-2019 average (black line). Note: A "P-case" is a GP consultation that resulted in a psychological diagnosis based on the ICPC-2 classification system (P00P99). The Figure uses three-week moving averages for the outcome variables. 


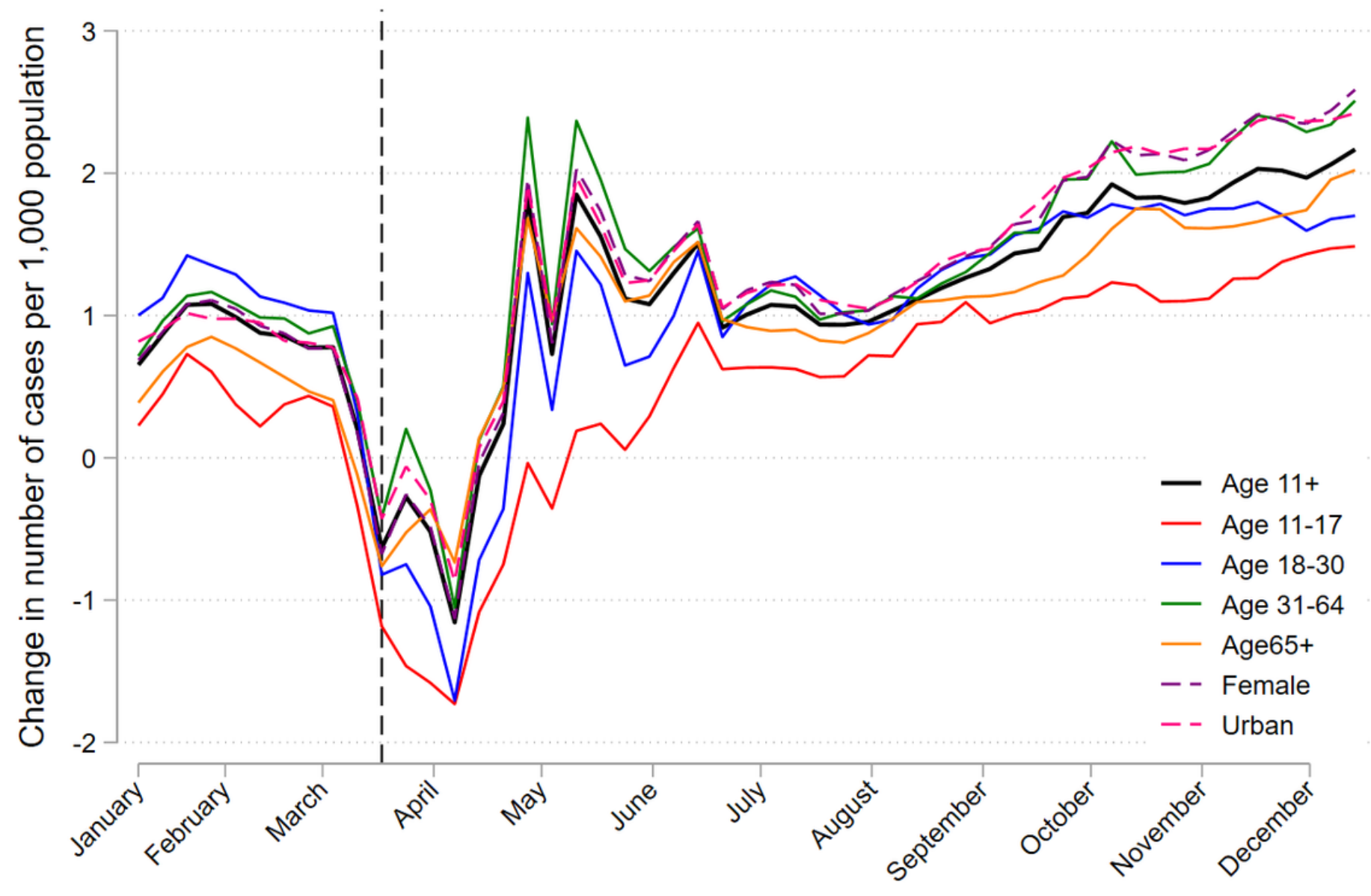

Figure 2

The increase in weekly number of P-cases in 2020 vs. 2017-2019 average for subpopulations, per 1000 capita subpopulation. Note: A "P-case" is a GP consultation that resulted in a psychological diagnosis based on the ICPC-2 classification system (P00-P99). "Population" on the y-axis refers to the number of individuals in the subpopulation that attended a GP during 2020. The Figure uses three-week moving averages for the outcome variable.

\section{Supplementary Files}

This is a list of supplementary files associated with this preprint. Click to download.

- SupplementaryAppendix.docx 